\title{
Is Long-Segment Fixation a Rule in Fractures Associated With Ankylosing Spondylitis?
}

\author{
ARVIND G. KULKARNI, MS (ORTH), VARUN K. AGARWAL, MS (ORTH), \\ NANDISH KUMAR KC, MS (ORTH), AVINASH KUMAR, MS (ORTH), ANKIT PATEL, MS (ORTH) \\ Department of Orthopaedics \& Spine Surgery, Bombay Hospital and Medical Research Centre, Mumbai, India
}

\begin{abstract}
Study Design: Technical report.

Objective: We describe the outcomes of percutaneous vertebroplasty in 3-columnar thoraco-lumbar fracture secondary to hyper-extension injury in 3 patients with ankylosing spondylitis (AS). Thoraco-lumbar hyperextension injuries in AS are generally unstable as they involve all 3 spinal columns and traditionally require long-segment posterior instrumented stabilization.

Methods: Three cases of AS with severe medical comorbidities underwent percutaneous vertebroplasty for hyperextension injury involving all 3 columns. Visual analog scale (VAS) and Oswestry Disability Index (ODI) scores were documented preoperatively, postoperatively, and at the last follow-up.

Results: Excellent improvements in VAS and ODI scores were achieved. The patients have no complaints and are independent and mobile at 2 years follow-up.

Conclusion: Vertebroplasty is an excellent option in such medically unfit patients with similar diagnosis and should be performed as early as possible before profound instability or neurological insult sets in, which would necessitate bigger and morbid surgeries.
\end{abstract}

Lumbar Spine

Keywords: ankylosing spondylitis, thoraco-lumbar spine fractures, hyper-extension injury, hyper-extension injury, instability, vertebroplasty, 3 column injuries

\section{INTRODUCTION}

The prevalence of vertebral fractures is $10 \%$ in patients with ankylosing spondylitis (AS). ${ }^{1}$ There is 7-fold increased fracture risk in AS patients as compared with healthy individuals. ${ }^{2}$ The hyperextension fractures in AS generally involve all 3 columns. ${ }^{3}$ Most surgeons/doctors advocate long-segment fixation and fusion in such injuries. ${ }^{3}$ The authors report 3 such cases in medically high risk and unfit patients that were successfully treated with percutaneous vertebroplasty under local anaesthesia with complete pain relief and immediate mobilization.

\section{MATERIALS, METHODS, AND RESULTS}

\section{Case 1}

A 61-year-old man with AS suffered a hyperextension injury following a domestic fall. The patient was in excruciating pain and was managed conservatively with bed rest and analgesics for 6 weeks. Because there was no relief of symptoms with conservative management, he was referred to the authors for further management. The patient was bed-ridden since the injury and had severe back pain (visual analog scale $[\mathrm{VAS}]=10 / 10$ ) at presentation. Neurological examination was normal. Patient was a known case of ischemic heart disease and had previously undergone a T9-10 laminectomy for myelopathy 5 years prior by the author (A.G.K.) and had fully recovered. Plain radiograph showed T12 vertebral fracture. Computed tomography (CT) and magnetic resonance imaging (MRI) of the thoracolumbar spine revealed features of AS and a transverse fracture through all 3 columns of T12 vertebra with no displacement (Figures 1 and 2). The patient's cardiac condition was extremely poor (ejection fraction was 15\%) and presented a high risk for general anaesthesia. In view of this, the authors decided that a long-segment instrumented fusion would carry a high risk of mortality and performed percutaneous vertebroplasty under local anaesthesia. Cook's needle was placed bilaterally in the vertebral body at the site of the fracture through 


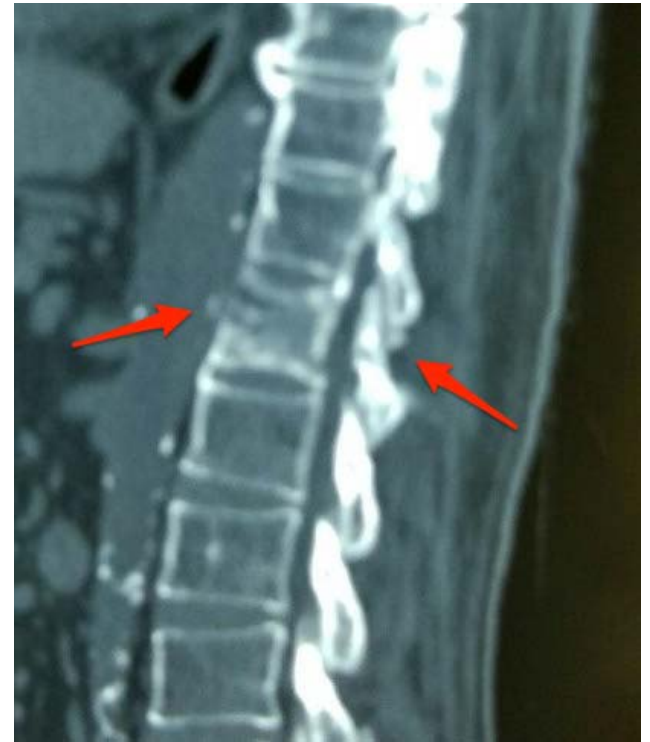

Figure 1. Sagittal computed tomography image showing a 3-column fracture of T12 in ankylosing spondylitis (Case 1).

the pedicles under fluoroscopic guidance and about $3 \mathrm{~mL}$ of bone cement was injected into the void (Figure 3). Appropriate precautions were taken to prevent cement leakage which included cement injection as anteriorly as possible (Figure 4) and turning the patient only after cement hardening. Postoperatively the patient was encouraged to resume walking 4 hours after the procedure with brace support (Figure 5). Follow-up CT showed adequate filling of the fracture site with bone cement (Figure 6) and excellent improvement in ODI and VAS scores were sustained at 2 years (Table).

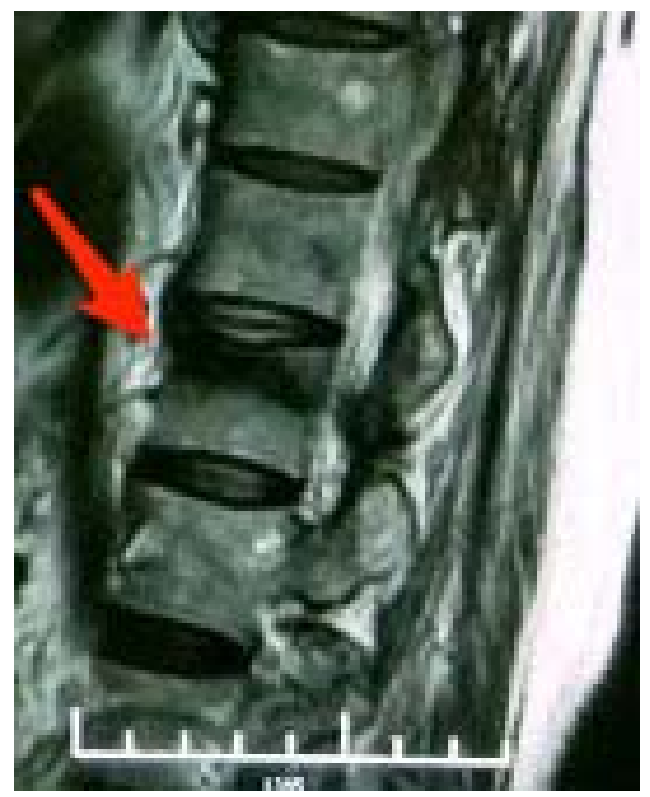

Figure 2. T2 sagittal magnetic resonance imaging showing hyperintense signal adjacent to superior end-plate of T12 vertebra indicating a fracture (Case 1).

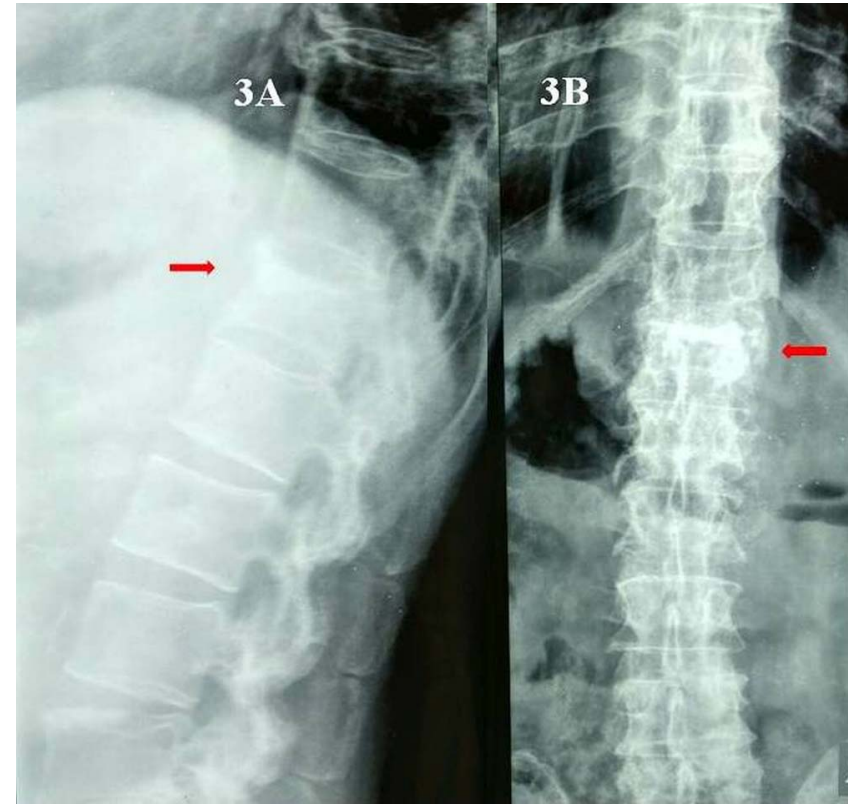

Figure 3. (A) Postoperative lateral radiograph of thoracolumbar spine highlighting vertebroplasty at T12 (red arrow; Case 1). (B) Postoperative antero-posterior radiograph of thoracolumbar spine highlighting the vertebroplasty done at T12 (red arrow; Case 1).

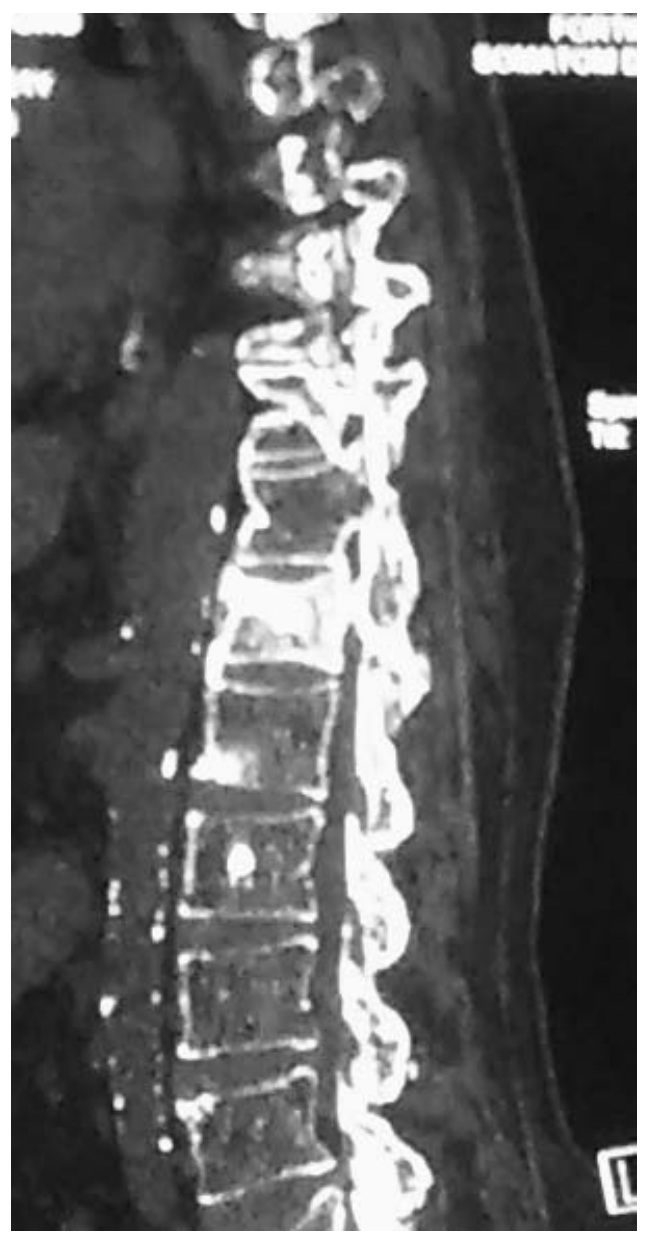

Figure 4. Postoperative sagittal computed tomography showing good penetration of cement at the fracture site (Case 2). 


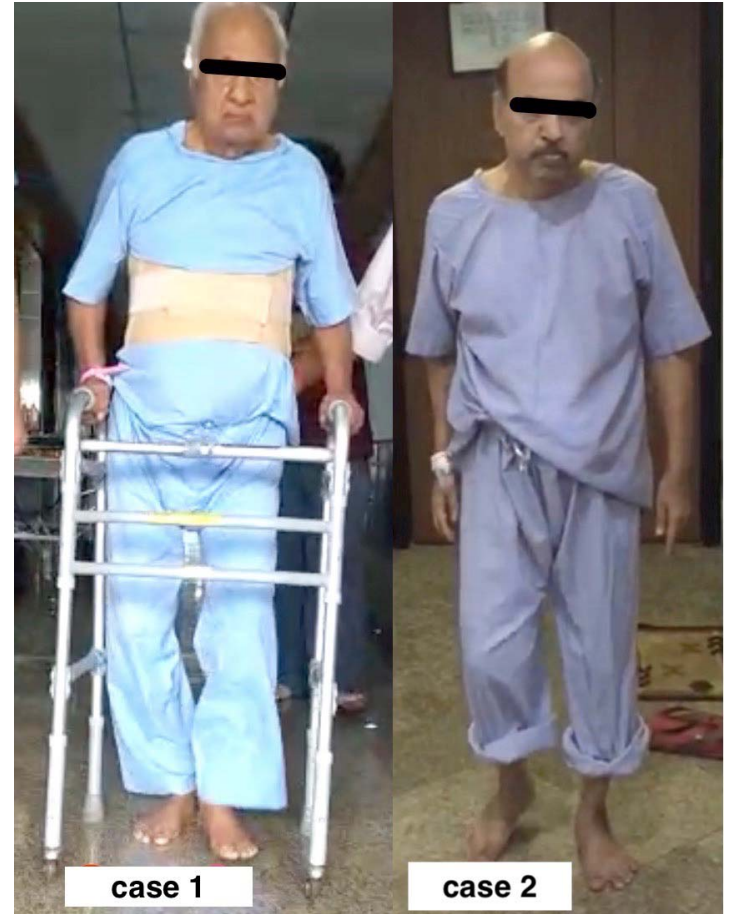

Figure 5. Patients mobilized on the same day of vertebroplasty procedure (Cases 1 and 2).

\section{Case 2}

An 88-year-old man, a known case of AS, presented after a fall at home 6 weeks prior with severe pain and not responding to conservative therapy. Due to extreme pain the patient was bedridden and unable to carry out activities of daily living. Clinical examination showed tenderness corresponding to T12 with no neurological involvement. A CT scan showed a transverse fracture just below the upper end plate of T12 vertebra involving all the 3 columns with no displacement (Figure 7). MRI showed hyper-intense signal on T2 images indicating fluid filling the fracture site resembling a pseudoarthrosis (Figure 8). The patient was a known case of diabetes and hypertension with 2D echo showing left ventricular hypertension, mitral regurgitation, tricuspid regurgitation, and severe pulmonary hypertension. His EF was $30 \%$ and as such, a high-risk for general anaesthesia and

Table. VAS and ODI of patients treated with vertebroplasty.

\begin{tabular}{lcccccc}
\hline $\begin{array}{l}\text { Case } \\
\text { No. }\end{array}$ & $\begin{array}{c}\text { Pre-Op } \\
\text { ODI }\end{array}$ & $\begin{array}{c}\text { Post-Op } \\
\text { ODI }\end{array}$ & $\begin{array}{c}\text { Follow-Up } \\
\text { ODI } \\
\text { (2 years) }\end{array}$ & $\begin{array}{c}\text { Pre-Op } \\
\text { VAS }\end{array}$ & $\begin{array}{c}\text { Post-Op } \\
\text { VAS }\end{array}$ & $\begin{array}{c}\text { Follow Up } \\
\text { VAS } \\
\text { (2 years) }\end{array}$ \\
\hline 1 & 72 & 16 & 02 & 10 & 3 & 1 \\
2 & 77 & 13 & 04 & 10 & 3 & 1 \\
3 & 84 & 15 & 04 & 10 & 2 & 1 \\
\hline
\end{tabular}

Abbreviations: ODI, Oswestry Disability Index; VAS, visual analog scale.

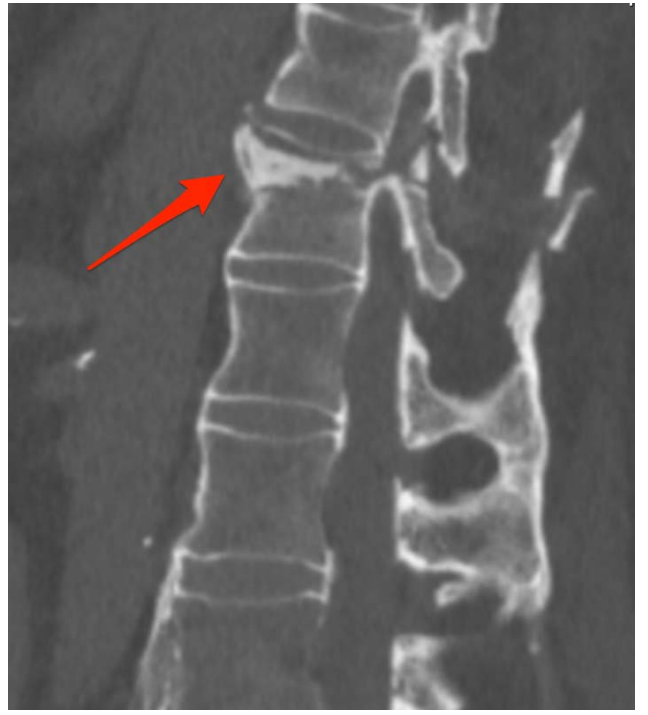

Figure 6. 2-year follow-up computed tomography sagittal image (Case 1).

prolonged surgery. Because of this, a decision to preform percutaneous vertebroplasty under local anaesthesia was taken using a method similar to what is described in Case 1. Postoperatively, the patient had immediate and dramatic pain relief. Postoperative CT scan showed adequate filling of the fracture with bone cement (Figure 4). He was encouraged to walk wearing a brace, with the aid of a walker for extra support, 4 hours after the procedure (Figure 5). We saw excellent improvement in ODI and VAS scores (Table). The outcomes were maintained at 2 years after the procedure.

\section{Case 3}

A 62-year-old man with AS reported after sustaining a fall in the bathroom with back pain that did not respond to conservative measures. CT and MRI showed transverse fracture of L2 with no displacement. Because he had low ejection fraction of $20 \%$ with restrictive lung disease, he was considered a poor risk for long-segment fixation. He was managed with percutaneous vertebroplasty under local anaesthesia. He had excellent pain relief postoperatively and was mobilized with a brace after 4 hours. ODI and VAS score showed excellent and sustained improvements at 2 years follow-up (Table).

\section{DISCUSSION}

AS is a debilitating condition leading to stiffness of the spine, or "bamboo spine." " Due to the stiffness, patients are extremely susceptible to fractures of the spine even following trivial trau- 


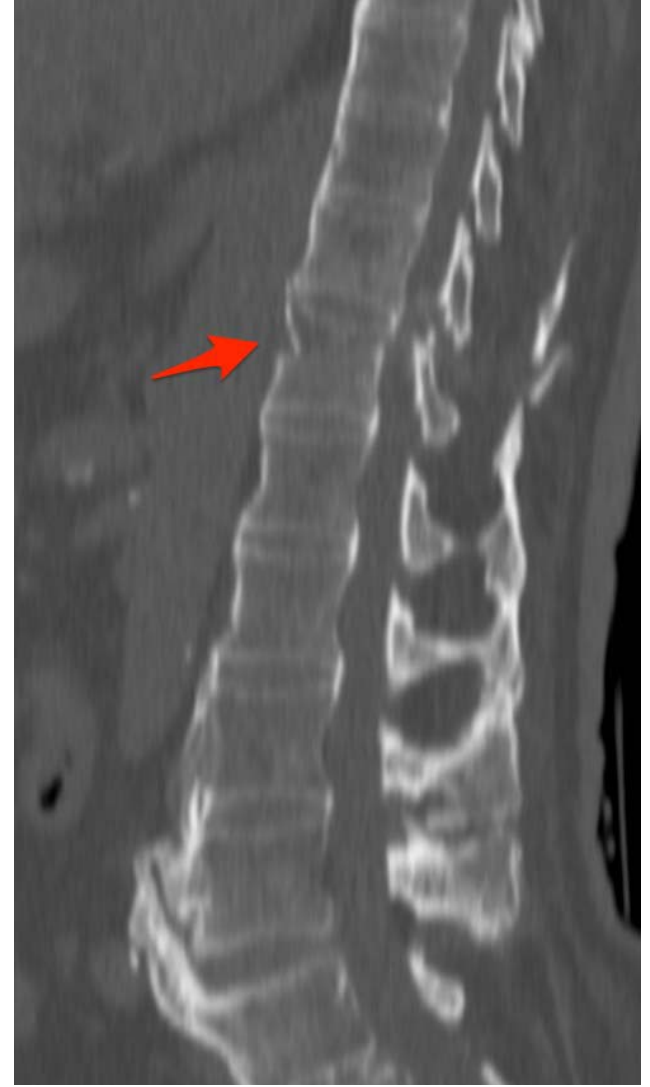

Figure 7. Computed tomography sagittal section showing fracture T12 involving all 3 columns (Case 2).

ma. ${ }^{5,6}$ The spinal fractures involve all 3 columns secondary to hyperextension injuries and behave like Chance fractures. ${ }^{7}$ The horizontal fracture line can run through vertebral body (bony Chance) or disc space (soft tissue Chance). ${ }^{8}$ Following the injury, the traumatic force acts on the long lever arm of ankylosed spine which behaves like a long extremity bone. ${ }^{3,9}$

In view of the focal instability at the fracture most surgeons/doctors advocate long-segment instrumented fusion. ${ }^{3,6,10}$ Generally, the mortality of surgicallytreated AS patients is higher than the normal population sustaining spinal trauma. ${ }^{6}$ Again, in patients with AS who are medically unfit for surgery, the issues related to management are further complicated in the absence of any set protocol. Brace treatment has been attempted in such cases with questionable relief and poor results. ${ }^{6,11,12}$ Specifically, brace treatment in AS patients has high incidence of pseudoarthrosis and consequent pain leading to delay in mobilization, which adds to the morbidity. ${ }^{6,13-15}$ Strategies to deal with such patients with persistent pain and high medical comorbidities that preclude surgery are lacking in the literature.

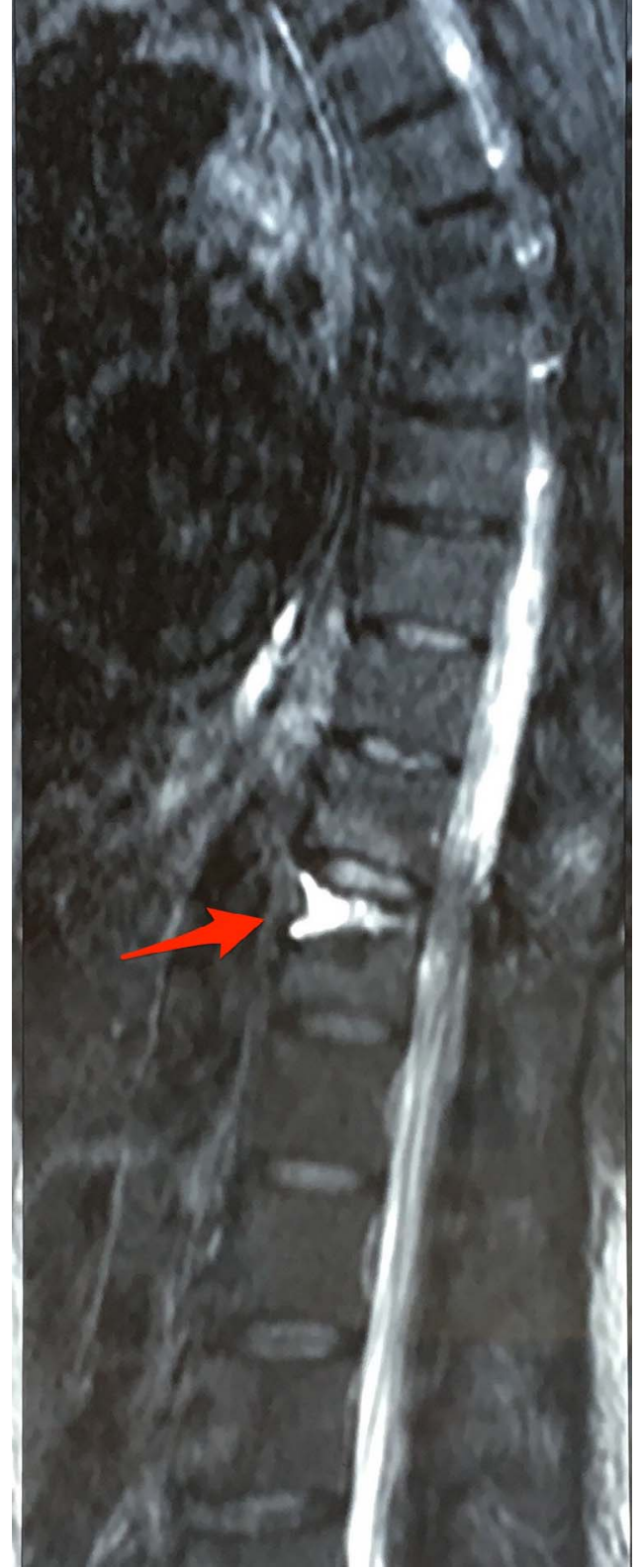

Figure 8. T2-weighted sagittal magnetic resonance imaging showing pseudoarthrosis (Case 2).

In such a situation, percutaneous vertebroplasty under local anaesthesia stands out as an excellent option. The pain and disability complicated by comorbidities in our patients was so extreme that an unconventional "out of box" management strategy had to be planned. The principle is to fill the void created by the fracture in the vertebral body with bone cement and establish the weight bearing continuity of the anterior column and thus minimize the impact of the posterior column injury. Kyphoplasty does not have any role in such cases because there is neither any need to open the fracture site (because of the hyperextension nature of injury, the 
fracture opens anteriorly like a fish mouth) nor any kyphosis that needs to be corrected. The successful outcome in the first operated case emboldened us to use the procedure in the consecutive 2 similar cases with successful outcomes.

Because repeated mobility at the fracture site can potentially cause lysis at the fracture site, gradually leading to profound instability, fibrous tissue formation, as well as neurological deficit, the authors suggest that such medically unfit patients with similar diagnosis should be treated aggressively with vertebroplasty as early as possible before there is a displacement at the fracture site. The procedure is relatively simple, less time-consuming, and associated with minimal morbidity, and the clinical benefit is exemplary in terms of quick pain-relief and rapid mobility. Early mobility with brace support on the same day of the procedure has beneficial consequences on the cardiorespiratory system in these patients whose age-related morbidity is compounded by restrictive lung disease and bed rest. A limitation of the procedure is that this technique can be used only for undisplaced fractures with no neurological involvement. Also, in view of the 3 column nature of the injury there is a risk of cement leakage posteriorly making it imperative to place the cement anteriorly. The risk of displacement at the fracture site is a possible complication that can occur after the procedure and the patient and relatives should be counseled regarding the same.

\section{CONCLUSION}

Long-segment instrumented fusion may not be a blanket treatment for all patients with AS. The dramatic pain relief and excellent recovery makes percutaneous vertebroplasty an invaluable asset in the treatment arsenal for this highly morbid subset of patients and can be performed early before profound instability or neurological insult sets in necessitating bigger and morbid surgeries.

\section{REFERENCES}

1. Davey-Ranasinghe N, Deodhar A. Osteoporosis and vertebral fractures in ankylosing spondylitis. Curr Opin Rheumatol. 2013;25(4):509-516.

2. Calin A, Fries JF. Striking prevalence of ankylosing spondylitis in "healthy" HLAB27 positive males and females. $N$ Engl J Med. 1975;293(17):835-839.

3. Westerveld LA, van Bemmel JC, Dhert WJA, Oner FC, Verlaan JJ. Clinical outcome after traumatic spinal fractures in patients with ankylosing spinal disorders compared with control patients. Spine J. 2014;14(5):729-740.
4. Braun J, Sieper J. Ankylosing spondylitis. Lancet. 2007;369(9570):1379-1390.

5. Bouxsein ML, Melton LJ, Riggs BL, et al. Age-and sexspecific differences in the factor of risk for vertebral fracture: a population-based study using QCT. J Bone Min Res. 2006;21(9):1475-1482.

6. Lee J K, Park KS, Park MS, Kim SM, Chung SY, Lee DS. Surgical treatment of lumbar hyperextension injury in ankylosing spondylitis. Korean J Spine. 2013;10(3):195-199.

7. Geusens P, Vosse D, van der Linden S. Osteoporosis and vertebral fractures in ankylosing spondylitis. Curr Opin Rheumatol. 2007;19(4):335-339.

8. Liu X, Bai R X, Li DD, Zhu B, Wu J. Analysis of the thoracolumbar fracture with ankylosing spondylitis. [In Chinese]. Zhongguo Gu Shang. 2009;22(7):488-490.

9. Einsiedel T, Schmelz A, Arand M, et al. Injuries of the cervical spine in patients with ankylosing spondylitis: experience at two trauma centers. J Neurosurg Spine. 2006;5(1):33-45.

10. Westerveld LA, Verlaan JJ, Oner FC. Spinal fractures in patients with ankylosing spinal disorders: a systematic review of the literature on treatment, neurological status and complications. Eur Spine J. 2009;18(2):145-156.

11. Glassman SD, Johnson JR, Holt RT. Seatbelt injuries in children. J Trauma. 1992;33(6):882-886.

12. Arkader A, Warner WC Jr, Tolo VT, Sponseller PD, Skaggs DL. Pediatric Chance fractures: a multicenter perspective. J Pediatr Orthop. 2011;31(7):741-747.

13. Weinstein PR, Karpman RR, Gall EP, Pitt M. Spinal cord injury, spinal fracture, and spinal stenosis in ankylosing spondylitis. J Neurosurg. 1982;57(5):609-616.

14. Fox MW, Onofrio BM, Kilgore JE. Neurological complications of ankylosing spondylitis. $J$ Neurosurg. 1993;78(6):871-878.

15. Johannes LB, Mirjam KV, Marieke NS, Irene EVHB, Barend JVR. Discovertebral (Andersson) lesions of the spine in ankylosing spondylitis revisited. Clin Rheumatol. 2009;28(8):883892.

Disclosures and COI: There is no conflict of interest among the authors or the institution regarding the manuscript, the scientific work or data collection. The legal regulatory status of the device(s)/drug(s) that is/are the subject of this manuscript is not applicable in our country. No funds were received in support of this work. No benefits in any form have been or will be received from a commercial party related directly or indirectly to the subject of this manuscript. There was no breach of ethical issues by any of the authors mentioned. The manuscript has been read and approved by the authors and each one of the authors treat their work trust worthy within all ethical parameters.

Corresponding Author: Arvind G. Kulkarni, MS (ORTH), Consultant Spine Surgeon, Mumbai Spine Scoliosis and Disc Replacement Centre, Room No. 206, Bombay Hospital \& Medical Research Centre, 12, New Marine Lines, 
Mumbai - 40020, India. Phone: +91-9892875490; Email: drarvindspines@gmail.com.

Published 30 April 2019

This manuscript is generously published free of charge by ISASS, the International Society for the Advancement of Spine Surgery. Copyright (c) 2019 ISASS. To see more or order reprints or permissions, see http://ijssurgery.com. 